\title{
PENGEMBANGAN MODUL PRAKTIKUM KIMIADASAR BERBASIS GREEN CHEMISTRY UNTUK MAHASISWA CALON GURU IPA
}

\author{
Arini Siti Wahyuningsih ${ }^{1}$ dan Jamilatur Rohmah ${ }^{2}$ \\ ${ }^{1}$ Prodi Pendidikan IPA, Universitas Muhammadiyah Sidoarjo \\ arinisitiwahyuningsih@umsida.ac.id \\ ${ }^{2}$ Prodi Analis Kesehatan, Universitas Muhammadiyah Sidoarjo \\ jamilaturrohmah@umsida.ac.id
}

\begin{abstract}
Abstrak
Kondisi lingkungan yang semakin mengkhawatirkan membuat seluruh pihak, tak terkecuali praktisi pendidikan, ingin berkontribusi mengatasi hal tersebut. Salah satu yang dapat dilakukan adalah dengan menghadirkan proses pembelajaran yang lebih peduli terhadap lingkungan. Dalam pendidikan sains, pendekatan Green Chemistry yang diintegrasikan dalam kegiatan laboratorium diharapkan mampu menjawab tantangan tersebut. Oleh karena itu, penelitian ini bertujuan untuk mengembangkan sebuah Modul Praktikum berbasis pendekatan Green Chemistry yang dapat digunakan mahasiswa calon guru IPA sebagai pedoman melaksanakan kegiatan praktikum yang aman dan ramah lingkungan pada mata kuliah Kimia Dasar. Metode penelitian ini adalah Research and Development (R\&D). Sasaran dalam penelitian ini adalah kelayakan modul tersebut berdasarkan penilaian ahli (dosen Kimia) dan mahasiswa. Data hasil penelitian dianalisis menggunakan metode analisis deskriptif kuantitatif. Berdasarkan hasil analisis data menunjukkan bahwa Modul Praktikum yang dikembangkan sangat layak untuk diimplementasikan dalam pembelajaran Kimia Dasar karena mendapat penilaian dengan kategori "sangat baik" dari dosen kimia pada ketiga aspek yaitu isi, petunjuk serta kesesuaian dengan prinsip Green Chemistry dan memperoleh respon yang sangat positif dari tanggapan mahasiswa sebagai pengguna modul tersebut.
\end{abstract}

Kata Kunci: Modul praktikum, Kimia Dasar, Pendekatan Green Chemistry, mahasiswa calon guru IPA

\section{Abstract}

Environmental conditions are increasingly worrying to make all parties, not least educational practitioners, want give to overcome it. One that can be done is by presenting a learning process that is more concerned about the environment. In science education, the Green Chemistry approach integrated into laboratory activities is expected to address these challenges. Therefore, this study aims to develop a practice Module based on Green Chemistry approach that can be used by prospective students of science teachers as guidance to carry out safe and environmentally friendly lab work on Basic Chemistry course. This research method is Research and Development $(R \& D)$. The aim of this research is the feasibility of the module based on expert assessment (lecturer of Chemistry) and students. The data of the research were analyzed using quantitative descriptive analysis method. Based on the results of data analysis shows that the developed practice Module is very feasible to be implemented in Basic Chemistry learning because it received an assessment with the category of "very good" from the chemistry lecturer on the three aspects of content, instructions and conformity with the principle of Green Chemistry and get a very positive response from Student responses as users of the module.

Keywords: Module lab, Chemistry Basic, Approach of Green Chemistry, student of science teacher candidate 


\section{Pendahuluan}

Keberlanjutan lingkungan menjadi isu yang sangat penting saat ini mengingat kondisi lingkungan yang semakin meresahkan. Menanggapi hal tersebut, Kementerian Pendidikan Dasar dan Menengah telah mengeluarkan peraturan no 54 tahun 2013 mengenai standar lulusan pendidikan dasar dan menengah yang harus memiliki perilaku bertanggung jawab dalam interaksinya yang efektif dengan masyarakat dan juga lingkungan. Peraturan ini ditetapkan dengan harapan agar generasi - generasi muda Indonesia memiliki rasa kepedulian yang tinggi terhadap lingkungan sehingga dapat berperan aktif untuk berpartisipasi mengatasi permasalahan lingkungan yang terjadi baik secara lokal maupun global.

Usaha untuk mewujudkan harapan tersebut tidak terlepas dari kecakapan dan keterampilan guru untuk menghadirkan proses pembelajaran yang lebih berwawasan lingkungan. Oleh karena itu, guru sebaiknya memiliki pengetahuan tentang lingkungan yang baik agar proses implementasi pembelajaran tersebut dapat berjalan efektif (Spiropoulou et al., 2007). Menurut Pe'er, Goldman, dan Yavetz (2007), apabila pengetahuan guru tentang lingkungan rendah maka akan berdampak pada perilaku siswa yang kurang bertanggung jawab terhadap lingkungan. Dengan demikian, membekali calon guru dengan pengetahuan yang cukup tentang lingkungan menjadi hal yang sangat penting agar nantinya dapat menumbuhkan sikap bertanggung jawab terhadap lingkungan kepada siswanya.

Pembelajaran yang lebih relevan dengan lingkungan dapat diperkenalkan kepada calon guru sejak semester awal perkuliahannya. Salah satunya dengan mengintegrasikan Education for Sustainable Development (ESD) ke dalam kurikulum pendidikan calon guru. ESD merupakan visi pendidikan yang menerapkan konsep pengembangan keberlanjutan dalam usaha untuk mengembangkan pengetahuan dan keterampilan mengenai keberlanjutan alam di masa yang akan datang serta mengubah orientasi nilai, perilaku dan gaya hidup melalui pendekatan yang menyeluruh dan interdisipliner (Unesco, 2009). Secara praktis, pendekatan Green Chemistry dapat dijadikan pijakan sebagai pendekatan yang mewakili visi ESD.

Gerakan Green Chemistry erat kaitannya dengan bagaimana mengatasi permasalahan lingkungan. Pendekatan ini digagas dengan 12 prinsip yang diharapkan mampu menjawab tantangan seputar polusi, krisis energi, limbah serta keamanan dan keselamatan kerja. Kontribusi pendekatan ini lebih diarahkan pada proses dan produk kimia yang lebih aman dan ramah dengan lingkungan dan kesehatan. Sejalan dengan hal itu, program studi Pendidikan IPA, Universitas Muhammadiyah Sidoarjo (Umsida) ingin memperkenalkan gagasan dalam pendekatan Green Chemistry melalui kegiatan laboratorium pada mata kuliah Kimia Dasar di semester awal perkuliahan mahasiswanya.

Kegiatan laboratorium dirasa tepat menjadi sasaran untuk mengenalkan konsep pengembangan keberlanjutan alam karena Septiana (2016) mengemukakan bahwa kegiatan di laboratorium yang berkenaan dengan praktikum kimia dapat menghasilkan limbah yang berbahaya juga apabila penggunaannya tidak diawasi dan dikontrol dengan baik. Caranya adalah dengan menerapkan beberapa prinsip Green Chemistry yang sesuai dengan setiap judul praktikum yang akan dikerjakan. Dengan begitu, mahasiswa calon guru IPA akan mengetahui bahwa praktikum yang dikerjakannya telah berbasis Green Chemistry menggunakan bahan yang tidak berbahaya, proses yang 
aman serta tidak menghasilkan limbah yang membahayakan lingkungan dan kesehatan.

Berdasarkan hasil observasi awal di Prodi Pendidikan IPA, Umsida, didapatkan informasi bahwa mahasiswa belum menggunakan modul praktikum sebagai panduan selama kegiatan laboratorium Kimia Dasar. Mahasiswa hanya menggunakan hand out yang dibuat oleh dosen yang diberikan saat melakukan praktikum. Kesempatan tersebut menjadi dasar analisis kebutuhan dikembangkannya modul praktikum untuk perkuliahan Kimia Dasar. Ditambahkan pula, modul praktikum yang akan dikembangkan menjadi sarana atau media untuk mengenalkan pendekatan Green Chemistry sehingga perlu dikembangkan modul praktikum Kimia Dasar berbasis Green Chemistry yang layak diimplementasikan kepada mahasiswa calon guru.

Modul praktikum Kimia Dasar dengan pendekatan Green Chemistry yang dikembangkan berbeda dengan modul serupa yang telah ada. Letak perbedaannya adalah yang pertama modul ini secara khusus ditujukan untuk mahasiswa calon guru IPA sehingga dibuat lebih terstruktur. Kedua, informasi mengenai pendekatan Green Chemistry dan 12 prinsipnya dicantumkan di bagian awal modul sebagai deskripsi pendekatan yang digunakan selama melakukan kegiatan laboratorium.

Ketiga, di setiap judul praktikum selain dilengkapi keterangan alat dan bahan yang secara umum memang ada di dalam sebuah modul praktikum, di dalam modul ini juga ditambahkan informasi mengenai sifat-sifat bahan yang digunakan sehingga mahasiswa mengetahui bagaimana karakteristik bahan yang digunakan serta cara menganggulangi apabila terjadi kontak langsung dengan bahan tersebut, prosedur atau cara yang tepat, misalnya untuk melakukan proses pemanasan, mencium bau zat atau gas hasil reaksi dan masih banyak lagi, dengan tujuan agar kegiatan laboratorium berjalan lancar, pembuangan limbah yang tepat sesuai dengan jenisnya. Keseluruhan komponen dalam modul ini disesuaikan dengan enam dari 12 prinsip dalam pendekatan Green Chemistry yaitu prinsip ketiga (sintesis kimia yang tidak berbahaya), keempat (merancang zat - zat kimia yang aman), kelima (penggunaan pelarut yang lebih aman), keenam (rancangan efisiensi energi), kesepuluh (rancangan proses penguraian) dan kedua belas (kimia yang lebih aman untuk mencegah terjadinya kecelakaan).

\section{Metode Penelitian}

Lokasi penelitian ini bertempat di Program Studi Pendidikan IPA, Universitas Muhammadiyah Sidoarjo (Umsida). Desain penelitian ini merupakan Research and Development (R\&D). Model pengembangan yang digunakan pada penelitian ini mengacu pada Prinsip Pengembangan Media menurut William W. Lee dan Diana L. Owens (2004) yang terdiri dari empat tahapan yakni (1) menyusun sebuah kerangka dari pengembangan alat, pengembangan spesifikasi, dan standarnya; (2) mengembangkan bagian-bagian dari media yang telah dicocokkan dengan kerangkanya; (3) meninjau dan perbaiki produknya; (4) mengimplementasikan produk akhirnya.

Pada tahap pertama yaitu menyusun kerangka dari pengembangan Modul Praktikum dilakukan analisis terhadap kegiatan laboratorium dan isi materi Kimia Dasar serta studi terhadap prinsip-prinsip pendekatan Green 
Chemistry. Analisis tersebut bertujuan untuk mengumpulkan informasi terkait Analisis kegiatan laboratorium dilakukan dengan obervasi secara langsung dan wawancara untuk mengetahui kegiatan praktikum yang berlangsung di laboratorium IPA, terutama Kimia Dasar, apakah sudah menggunakan bahan kimia dan proses yang ramah lingkungan serta prosedur yang aman bagi mahasiswa. Analisis isi materi Kimia Dasar dilihat berdasarkan Rencana Pembelajaran Semester (RPS) yang telah divalidasi oleh Tim Kurikulum Universitas. Selanjutnya, studi pendekatan Green Chemistry untuk menentukan prinsip Green Chemistry yang disesuaikan dengan prosedur setiap judul praktikum. Prinsip - prinsip tersebut diharapkan dapat membantu mahasiswa calon guru untuk mengenal bahan - bahan kimia yang aman dan yang berbahaya sehingga tahu cara menggunakannya serta prosesnya yang lebih ramah lingkungan.

Tahap yang kedua adalah mengembangkan Modul Praktikum yang sesuai dengan kerangka pada tahap pertama. Hasil dari tahap kedua adalah draf 1 atau desain awal Modul Praktikum.

Tahap selanjutnya adalah meninjau dan memperbaiki Modul Praktikum. Di dalam tahap ini, draf 1 Modul Praktikum melalui proses telaah, validasi dan revisi hingga akhirnya menghasilkan draf 3 yang siap diimplementasikan pada tahap uji coba kepada mahasiswa calon guru IPA. Proses telaah dilakukan oleh teman sejawat untuk meminta masukan dan saran mengenai desain awal modul. Setelahnya, draf 1 modul direvisi sesuai saran yang telah diberikan oleh teman sejawat dan dihasilkan draf 2. Kemudian, draf 2 tersebut divalidasikan kepada ahli yaitu dosen Kimia dari Program Studi Kimia Analitik, Umsida. Penilaiannya meliputi tiga aspek yakni petunjuk, isi dan kesesuaian dengan pendekatan Green Chemistry. dengan kebutuhan akan Modul Praktikum yang dikembangkan.

Berikutnya, draf 2 modul direvisi kembali sesuai dengan penilaian dan saran yang diberikan oleh ahli sehingga menghasilkan draf 3 yang siap digunakan pada tahap ujicoba kepada 18 mahasiswa calon guru IPA yang sedang menempuh semester 1 perkuliahannya. Uji coba dilaksanakan dengan tujuan untuk mengetahui penilaian mahasiswa sebagai user terhadap modul yang dikembangkan. Instrumen yang digunakan antara lain angket respon mahasiswa dan jurnal reflektif. Hasil respon mahasiswa akan dianalisis dan pada akhirnya dapat ditarik kesimpulan bagaimana kualitas Modul Praktikum Kimia Dasar dengan pendekatan Green Chemistry yang telah dikembangkan berdasarkan penilaian ahli dan mahasiswa.Data hasil penelitian berupa penilaian dari Dosen Kimia dan respon dari mahasiswa dianalisis dengan cara menghitung rerata skor dan menentukan kriteria interpretasi skor. Indikator kelayakan Modul Praktikum apabila rerata skor hasil penilaian Dosen Kimia lebih dari 3,40 (Riduan, 2010).

Tabel 1 Interpretasi Skor Kelayakan Modul Praktikum

\begin{tabular}{cc}
\hline Interval Skor & Kategori Penilaian \\
\hline $4,20<$ Skor $\leq 5,00$ & Sangat Baik \\
& \\
$3,40<$ Skor $\leq 4,19$ & Baik \\
$2,60<$ Skor $\leq 3,39$ & Cukup \\
$1,80<$ Skor $\leq 2,59$ & Kurang \\
$1,00 \leq$ Skor $\leq 1,79$ & Sangat Kurang \\
\hline
\end{tabular}

Sedangkan indikator kelayakan berdasarkan respon mahasiswa apabila mencapai rerata skor lebih dari 0,49 (Sugiyono, 2012). 


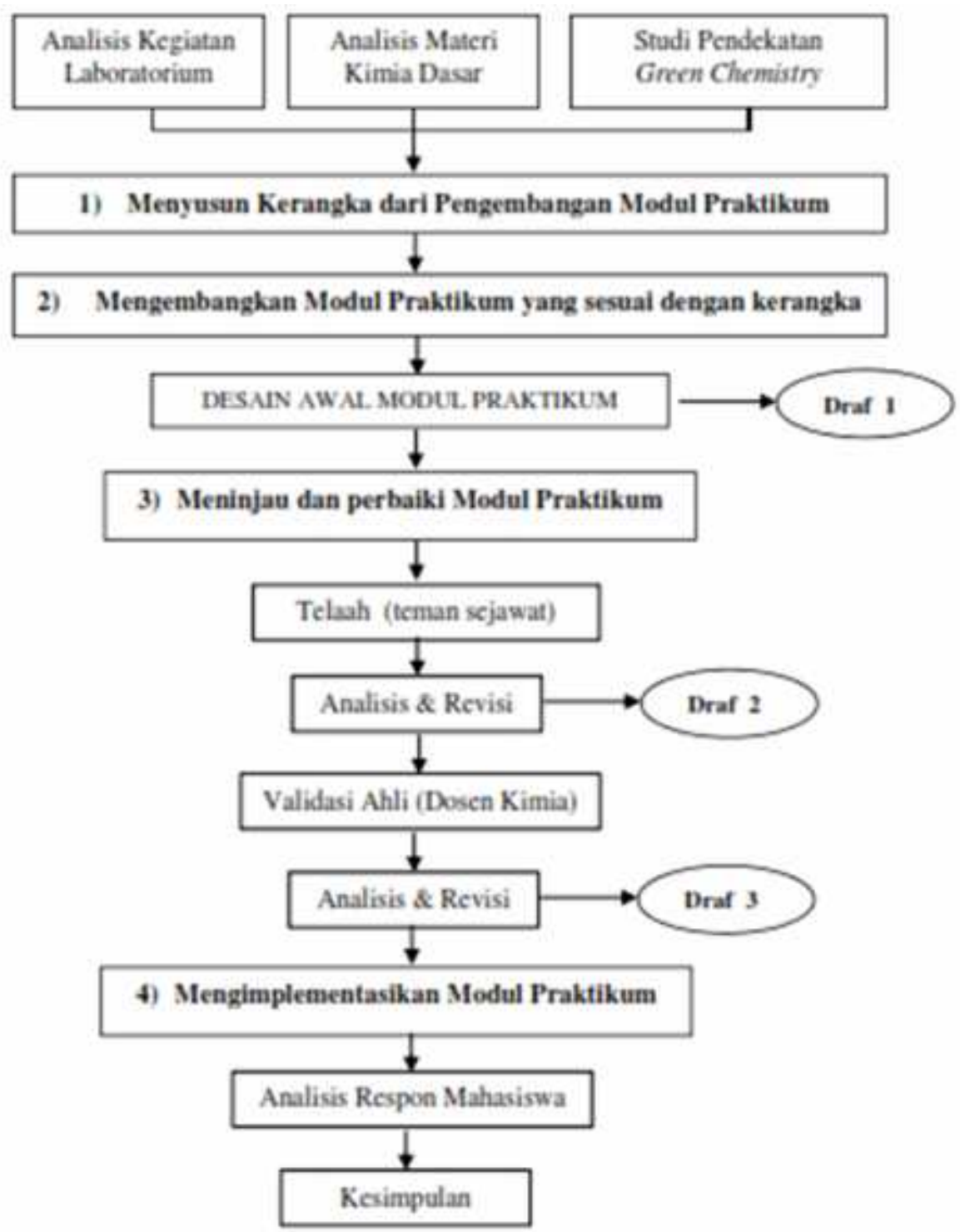

Gambar 1. Model Pengembangan Modul Praktikum Kimia Dasar Berbasis Green Chemistry

Tabel 2 Interpretasi Skor Kelayakan berdasarkan respon mahasiswa

\begin{tabular}{cl}
\hline Interval Skor & \multicolumn{1}{c}{ Kategori Penilaian } \\
\hline 1 & Setuju \\
$0,51-0,99$ & Mendekati Setuju (MS) \\
0,50 & Agak Setuju (AS) \\
$0,01-0,49$ & Mendekati Tidak Setuju (MTS) \\
0 & Tidak Setuju (TS) \\
\hline
\end{tabular}




\section{Hasil Penelitian dan Pembahasan}

Pengembangan modul praktikum Kimia Dasar berbasis Green Chemistry yang layak dapat digunakan oleh mahasiswa calon guru IPA menjadi tujuan utama dalam penelitian ini. Hasil dari empat tahap pengembangan modul praktikum ini akan dijabarkan sebagai berikut:

\section{Data Hasil Penyusunan Kerangka Modul Praktikum}

Data yang mewakili tahap pertama pengembangan modul ini terbagi menjadi data analisis kegiatan laboratorium, materi mata kuliah Kimia Dasar dan studi pendekatan Green Chemistry. Yang pertama, data hasil analisis kegiatan laboratorium berdasarkan hasil observasi langsung dan wawancara menunjukkan bahwa kegiatan laboratorium mata kuliah Kimia Dasar selama ini belum menggunakan modul praktikum sebagai panduan mahasiswanya. Mahasiswa calon guru dari program studi Pendidikan IPA ini hanya difasilitasi hand out yang diberikan apabila akan praktikum. Hal ini tentu saja menjadi kendala bagi mahasiswa untuk memahami alat, bahan dan prosedur kerja percobaan. Yang kedua, berdasarkan hasil analisis terhadap materi Kimia Dasar yang dijabarkan dalam RPS dirumuskan lima judul praktikum Kimia Dasar antara lain Senyawa Ionik dan Kovalen, Perhitungan Kimia, Reaksi Kimia, Kalorimeter dan Faktor yang Mempengaruhi Laju Reaksi. Yang ketiga, studi pendekatan Green Chemistry menghasilkan prinsip - prinsip apa saja yang digunakan pada setiap judul praktikum. Tabel 3 merangkum prinsip Green Chemistry yang digunakan pada setiap judul praktikum Kimia Dasar.

Data ketiga hasil analisis tersebut menjadi dasar penyusunan kerangka modul praktikum Kimia Dasar berbasis Green Chemistry.

Tabel 3. Prinsip Green Chemistry dalam Modul Praktikum Kimia Dasar

\begin{tabular}{lll}
\hline \multicolumn{1}{c}{ Judul Praktikum } & \multicolumn{1}{c}{ Prinsip Green Chemistry } \\
\hline Senyawa Ionik dan Kovalen & - Prinsip ketiga (sintesis kimia yang tidak berbahaya) \\
& - Prinsip keempat (merancang zat kimia yang aman) \\
& - Prinsip kelima (penggunaan pelarut yang lebih aman) \\
& - Prinsip keenam (rancangan efisiensi energi) \\
& - Prinsip kesepuluh (rancangan proses penguraian) \\
Perhitungan Kimia & - Prinsip ketiga (sintesis kimia yang tidak berbahaya) \\
Reaksi Kimia & - Prinsip kesepuluh (rancangan proses penguraian) \\
& - Prinsip kesepuluh (rancangan proses penguraian) \\
Kalorimeter & - Prinsip kedua belas (kimia yang lebih aman untuk \\
& - Prinsip ketiga (sintesis kimia yang tidak berbahaya) \\
& - Prinsip keempat (merancang zat kimia yang aman) \\
Faktor yang & - Prinsip kelima (penggunaan pelarut yang lebih aman) \\
laju reaksi & - Prinsip kelima (penggunaan pelarut yang lebih aman) \\
& & Prinsip kesepuluh (rancangan proses penguraian) \\
& &
\end{tabular}




\section{Data Hasil Pengembangan Modul Praktikum}

Kerangka yang dihasilkan dari tahap pertama menjadi acuan dalam mengembangkan modul praktikum ini. Pada tahap pengembangan modul terbagi atas dua bagian yakni perancangan awal dan isi. Bagian awal modul terdiri atas (1) sampul modul, (2) kata pengantar, (3) daftar isi, (4) tata tertib, (5) penilaian praktikum, (6) prosedur umum pelaksanaan praktikum, (7) sistematika penulisan laporan, (8) pengenalan alat laboratorium, (9) pendekatan Green Chemistry dan (10) deskripsi praktikum Kimia Dasar.

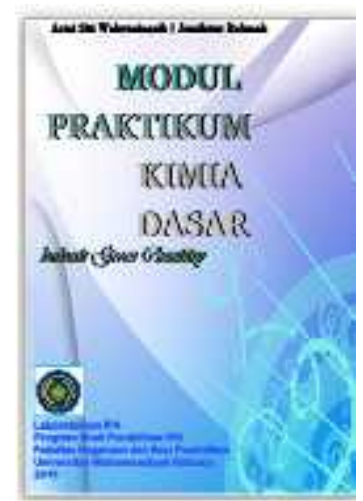

Gambar 1. Sampul Depan Modul

Sedangkan bagian isi merupakan rancangan setiap judul praktikum yang terdiri atas komponen: (1) judul praktikum, (2) pendahuluan, (3) persiapan, (4) alat dan bahan, (5) prinsip Green Chemistry, (6) prosedur percobaan, (7) tabel data percobaan, (8) analisis/Diskusi, (9) simpulan dan (10) daftar pustaka.

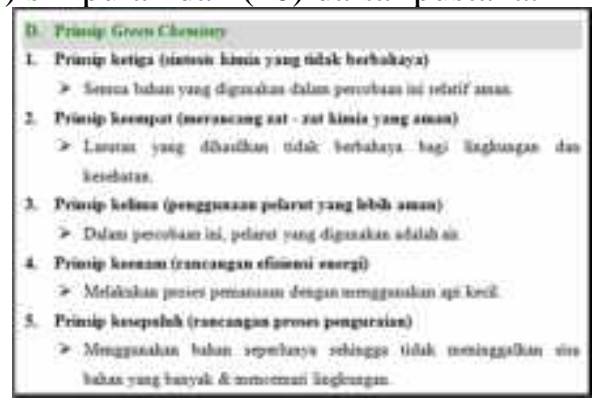

Gambar 2. Sampul Depan Modul
Desain atau draft 1 adalah hasil dari tahap pengembangan modul praktikum.

\section{Data Hasil Peninjauan dan Perbaikan Modul Praktikum}

Tahap ini dimulai dengan telaah oleh teman sejawat terhadap desain atau draft 1 modul. Saran dan masukan yang diberikan lebih pada komponen dalam bagian isi yaitu rancangan setiap judul praktikum seperti alat dan bahan, prosedur dan tabel data percobaan. Draft 1 modul mengalami perbaikan dan menghasilkan draft 2 modul.

Setelah draft 2 terbentuk, maka dilakukan validasi oleh validator yaitu dosen Kimia dari Fakultas Ilmu Kesehatan, Umsida. Pendapat dari validator yang meliputi tiga aspek yaitu petunjuk, isi dan kesesuaian dengan prinsip Green Chemistry digunakan sebagai penilaian kualitas modul praktikum yang dikembangkan.

Tabel 4. Hasil Validasi Dosen Kimia

\begin{tabular}{ccc}
\hline $\begin{array}{c}\text { Aspek } \\
\text { Penilaian }\end{array}$ & Skor & Keterangan \\
\hline Petunjuk & 3,67 & Sangat Baik \\
Isi & 3,83 & Sangat Baik \\
Pendekatan & 4,00 & Sangat Baik \\
Green & & \\
Chemistry & & \\
\hline Rata-rata & $\mathbf{3 , 8 3}$ & Sangat Baik \\
\hline
\end{tabular}

Berdasarkan hasil validasi pada Tabel 3, Modul Praktikum Kimia Dasar dengan pendekatan Green Chemistry memperoleh penilaian dari dosen Kimia pada rentang sangat baik karena mendapatkan skor > 3,4 (Riduan, 2010). Artinya, Modul Praktikum Kimia Dasar layak untuk diimplementasikan dalam proses pembelajaran mata kuliah Kimia Dasar tetapi dengan saran dan revisi kecil di beberapa bagian Modul Praktikum seperti prosedur praktikum, alat dan bahan. Saran yang diberikan validator yaitu tentang perbaikan jumlah bahan yang digunakan, 
revisi jenis dan jumlah alat yang digunakan serta revisi runtutan prosedur praktikum. Oleh karena itu, nilai tertinggi diberikan validator untuk aspek kesesuaian dengan prinsip Green Chemistry sedangkan nilai aspek petunjuk dan isi mendapat nilai yang lebih rendah. Dengan demikian, validator berpendapat bahwa kegiatan praktikum mata kuliah Kimia Dasar telah sesuai dengan pendekatan Green Chemistry karena menggunakan bahan yang ramah lingkungan dan konsentrasinya rendah, prosedur aman dilakukan, serta tidak menghasilkan limbah yang berbahaya bagi lingkungan dan kesehatan.

Draft 2 yang diberi masukan oleh validator direvisi dan menghasilkan draft 3. Draft ketiga tersebut akan digunakan pada tahap akhir pengembangan modul ini yaitu implementasi modul praktikum yang dikembangkan kepada mahasiswa calon guru sebagai pengguna (user).

\section{Data Hasil Implementasi Modul Praktikum}

Mahasiswa calon guru IPA sebagai pengguna juga memberikan penilaian terhadap kualitas modul praktikum dengan pendekatan Green Chemistry yang dikembangkan. Instrumen yang digunakan adalah angket respon mahasiswa yang diadaptasi dari angket respon siswa yang dikembangkan oleh Septiana (2016).

Terdapat 18 pertanyaan tertulis di dalam angket tersebut yang mewakili empat aspek yaitu 1) tingkat kejelasan kalimat dan keterbacaan, 2) keterlaksanaan praktikum, 3) tampilan fisik modul dan 4) pendekatan Green Chemistry. Respon mahasiswa terhadap modul diberikan berdasarkan skala Guttman yang digunakan dalam angket tersebut.
Tabel 5. Data Respon Mahasiswa

\begin{tabular}{ccc}
\hline $\begin{array}{c}\text { Aspek } \\
\text { Penilaian }\end{array}$ & $\begin{array}{c}\text { Respon } \\
\text { Setuju }\end{array}$ & $\begin{array}{c}\text { Respon Tidak } \\
\text { Setuju }\end{array}$ \\
\hline Kejelasan & 0,92 & 0,08 \\
kalimat dan & (Mendekati & (Mendekati \\
keterbacaan & Setuju) & Tidak Setuju) \\
Tampilan & 0,85 & 0,15 \\
Fisik Modul & (Mendekati & (Mendekati \\
& Setuju) & Tidak Setuju) \\
Keterlaksan & 0,96 & 0,04 \\
aan & (Mendekati & (Mendekati \\
praktikum & Tidak Setuju) & \\
Pendekatan & 0,97 & 0,03 \\
Green & (Mendekati & (Mendekati \\
Chemistry & setuju) & Tidak Setuju) \\
\hline & &
\end{tabular}

Hasil yang ditunjukkan tabel 5 menunjukkan bahwa respon mahasiswa calon guru IPA sebagai pengguna modul praktikum Kimia Dasar berbasis Green Chemistry sangat positif. Terlihat keempat aspek mencapai rerata skor lebih dari 0,49 (Sugiyono, 2012). Rerata skor respon mahasiswa paling rendah diperoleh aspek tampilan fisik modul karena beberapa mahasiswa menilai bahwa sampul modul kurang menarik dan gambarnya kurang proporsional. Sedangkan rerata skor respon mahasiswa tertinggi terdapat pada aspek pendekatan Green Chemistry karena hampir seluruh mahasiswa menilai bahwa kegiatan praktikum yang dilakukan telah menerapkan prinsip - prinsip Green Chemistry mulai dari bahan yang digunakan ramah lingkungan dan aman, tidak menghasilkan banyak limbah, produk yang dihasilkan juga aman dan tidak menimbulkan limbah berbahaya serta prosedur kerja yang aman bagi mahasiswa dan lingkungan.

\section{Kesimpulan dan Saran}

Modul praktikum Kimia Dasar dengan pendekatan Green Chemistry 
dikembangkan dengan karakteristik integrasi 6 prinsip Green Chemistry telah dinyatakan layak karena mendapat penilaian dengan kategori sangat baik dari ahli dan mahasiswa. Hal ini berarti modul tersebut dapat digunakan sebagai bahan ajar pada mata kuliah Kimia Dasar yang menjamin seluruh kegiatan praktikum berjalan aman dan ramah bagi lingkungan serta kesehatan. Sekaligus media untuk mengenalkan konsep pengembangan berkelanjutan untuk membekali pengetahuan calon guru IPA tentang lingkungan dengan harapan dapat menjadi pendidik yang menghadirkan kegiatan pembelajaran lebih relevan dan responsif terhadap lingkungan bagi siswanya nanti.

\section{Daftar Pustaka}

Lee, William L dan Owens, Diana L. (2004). Multimedia-based Instructional Design: Computerbased. San Francisco: John Wiley \& Sons.

Pe'er, S., Goldman, D., and Yavetz, B. (2007). Environmental Literacy in Teacher Training: Attitudes, Knowledge, and Environmental Behaviour of Beginning Students. The Journal of Environmental Education. Vol 39, No. 1, pp. 4559.

Riduwan. (2010). Dasar-dasar Statistika. Bandung: Alfabeta

Septiana, Nurul. (2016). Pengembangan Buku Petunjuk Praktikum Kimia Berbasis Green Chemistry untuk SMA/MA Kelas XI Semester 2. (Skripsi Pendidikan Kimia tidak dipublikasikan). Universitas Islam Negeri Sunan Kalijaga Yogyakarta. Spiropoulou, D., Antonakaki, T., Kontaxakaki, S., and Bouras, S. (2007). Primary Teachers' Literacy and Attitudes on Education for Sustainable Development. Journal of Science Education and

Technology. Vol 16, pp. 443-450.

Sugiyono. (2012). Metode Penelitian

Pendidikan (Pendekatan

Kuantitatif, Kualitatif, dan $R \& D)$.

Bandung: Alfabeta.

UNESCO. (2009). Review of Contexts and Structures for Education for

Sustainable Development. Paris:

Division for the Coordination of

United Nations Priorities in Education. 